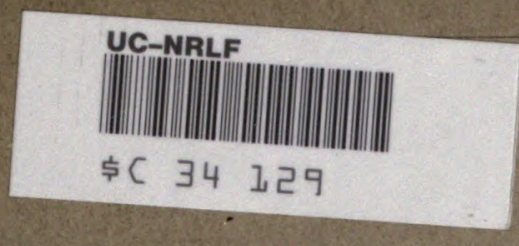

ON THE IDENTITY

OF THE

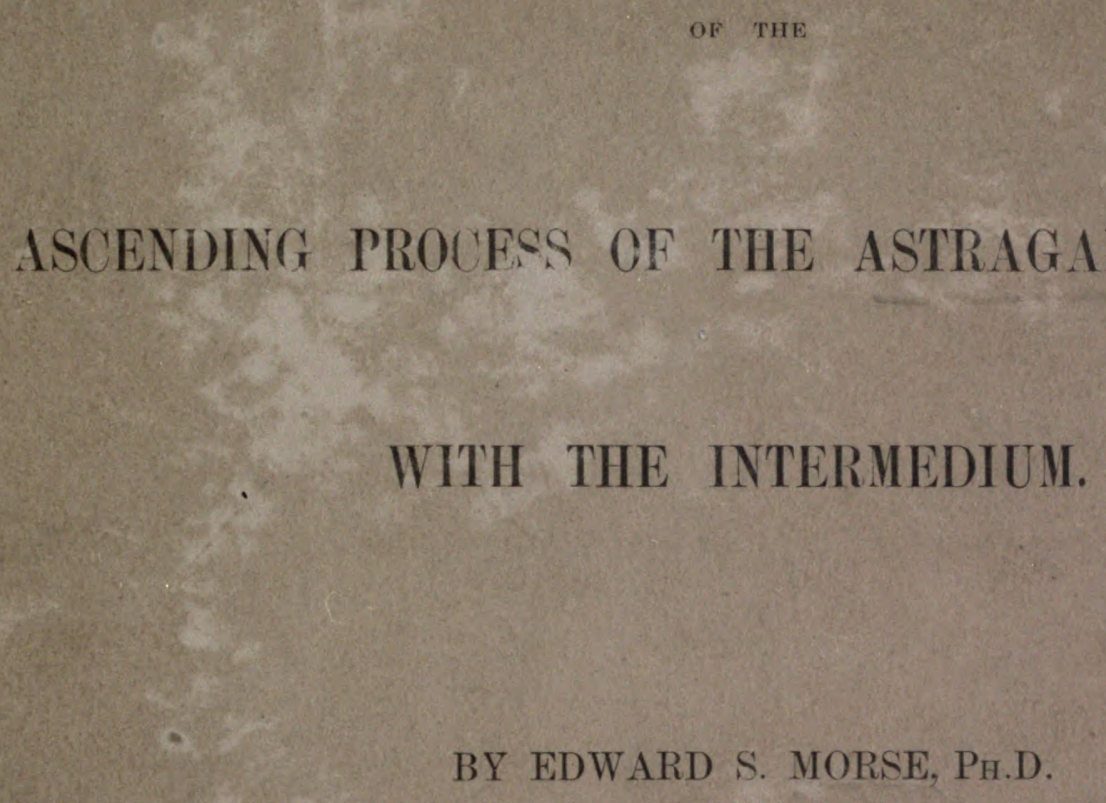

BOSTON :

PUBLISHED BY THE SOCIETY.

1880. 

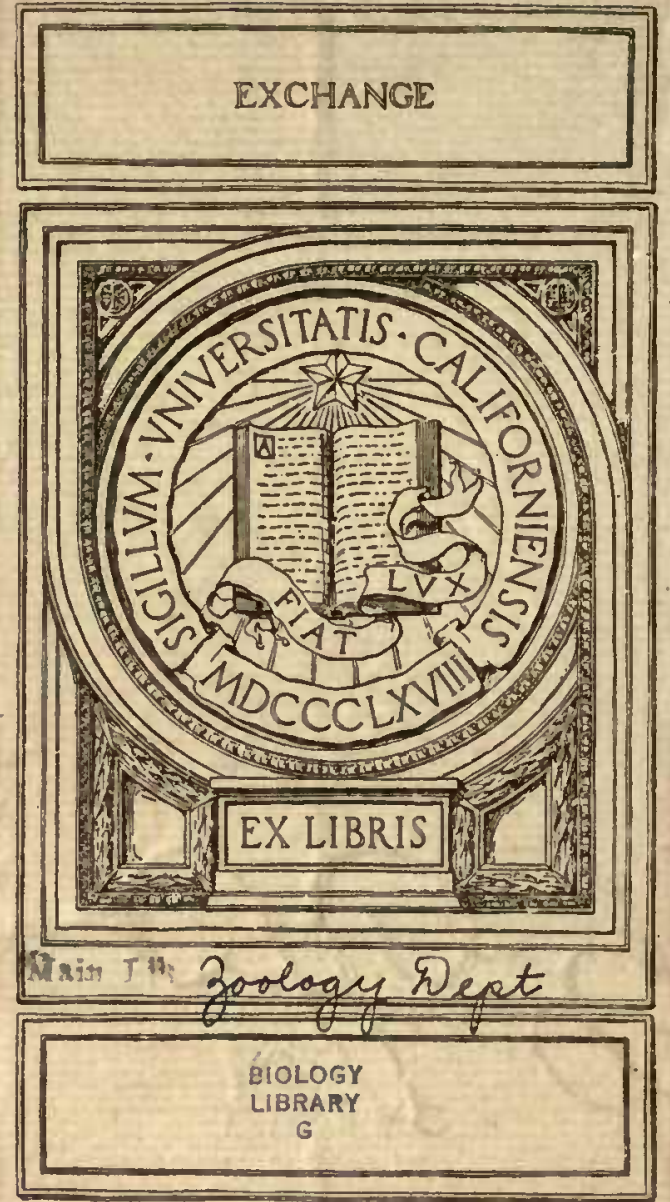


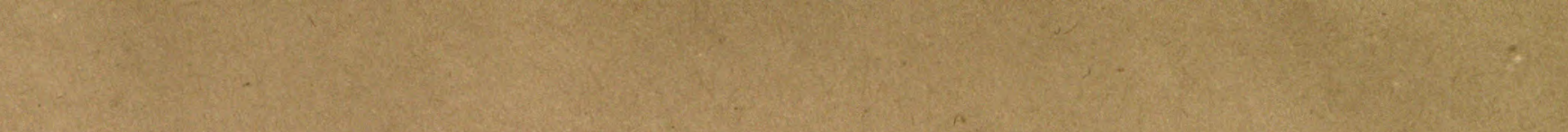
.

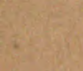


1830. ANIVERSARY MEMOIRS OF TIIE BOSION SOCIETY OF NATURAL HISTORY. 1850.

\section{ON THE IDENTITY}

OF THE

\section{ASCENDING PROCESS OF THE ASTRAGALUS IN BIRDS}

\section{WITII THE INTERMIEDIUN.}

BY EDWARD S. MORSE, Ph.D.

BOSTON :

PUBLISHED BY THE SOCIETY.

1880. 
Mb

wax Libigtol is ept

$\because \because \therefore \quad \therefore \because \because \vdots \vdots$

$\therefore \because \because \because \because \vdots \vdots \cdots \cdots$ 
On tile Identity of tile Ascending Process of the Astragalus in Birds with the Intermedium. By Edward S. Morse.

FROM the time that Hermann Von Meyer, fifty years ago, first recognized that the Triassic reptiles had characters which removed them widely from living forms, anatomists and palaeontologists have been diligently at work defining with greater exactness the anatomical features of these early animals. The results of these labors have been to increase the distinctions between these forms and their supposed living representatives, and to erect for some of them new orders in the old class of Reptiles. Nor has this been the only result; through Professor Cope's $(I, 2,3)$ studies of the Dinosaurs of the Greensand of New Jersey, avian affinities were pointed out which were subsequently and independently. confirmed by Professor Huxley $(4,5)$.

With the gradual unfolding of these features, the unquestionable reptilian charaster of the group with its unmistakable avian pelvis and hind limb became evident.

The birds whose affinities with other classes had been so obscure as to have caused them to be designated as a closed type, beeame better understood; for the key to their mysterious affinities was found in the rocks of the Mezozoic age, and in the transient features of their own embryos.

With the closer approximation of the Reptiles and Birds by Huxley, under the greater division Sauropsida, our only wonder is that relationships so plain had never before been recognized. Gegenbaur's (6) determination of the more important elements of the tarsus in Birds, and the rapid growth of our knowledge of the Dinosaurians through the labors of Leidy, Cope, Marsh and Huxley, have gradually strengthened the conviction that among the Dinosaurs, or closely related forms, we were to look for the progenitors of the present birds.

Professor H. G. Seeley (7), in a lecture on the Dinosauria, delivered before the Scientific Club of Vienna, while admitting for them a few avian characters, considers that some relations have been overrated, and that the avian affinities of the Dinosaurians were not so strong as had been supposed. It seens to me, however, that he does not give'sufficient importance to the fact that some of these relations liave been based on the characters presented by birds in an advanced stage of embryonic growth, that is to say in enbryos so far advanced, that all the leading avian features had been established.

While Professor Seeley admits certain avian characters in the lind limbs of some Dinosaurians, he says that they are limited to two points: "First, the development of a strong anterior crest, which is directed forward and outward, so as to extend in front of 
the fibula, is a Dinosaurian character met with to some extent among birds, but quite as well marked in mammals. Secondly, the shape of the distal end of the bone is birdlike; but that form is found in no adult bird, and is only to be detected in the young bird before the tarsus had become blended with it, so that while it might go to show, pcrhaps, that birds are descended from a common stock with Dinosaurs, it would be misleading to regard it as altogether avian, since the character is lost in the adult bird's skeleton" (page 57). And furthermore, he says, "But when the tarsus, or rather, the astragalus, is closely applied to the tibia, as in Megalosaurus, Poecilopleuron, Laelaps, or Iguanodon, it gives the bone a resemblance to the birds which is almost convineing, since the parallel extends to nearly every detail. The character, however, is shorn of much of its importance, when we remember that there are many Dinosaurs in which there is an os calcis, or heel-bone, placed side by side with the astragalus."

Professor Seeley is aware that in Laelaps the hour-glass shaped tarsal bone represents the os calcis and astragalus connate; also that Prof. Cope shows that these two bones are ankylosed in Ornithotarsus.

The memoir of Gegenbaur on the Tarsus and Carpus of Birds had, for the moment, probably escaped the attention of Prof. Seeley.. In this contribution of Gegenbaur's the separation of the tarsal portion into two bones, the upper and under tarsal bone, is clearly pointed out. Furthermore, Gegenbaur shows two centres of ossification in the upper, or proximal bone, which he rightly infers to represent the tibiale and fibulare (these names are used in preference to those of astragalus and os calcis, as better defining the relations existing between them and the tibia and fibula). These demonstrations were based on an examination of the chick at a late stage of embryonic growth.

In my memoir (8), on the Tarsus and Carpus of Birds, I not only fully confirmed the observations of Gegenbaur, but showed the absolute separation of these two elements as tibiale and fibulare, based on an examination of a number of species of birds at an earlier stage than those examined by Gegenbaur. Figures of these were also given, showing the fibula, with the same length as the tibia, and nearly approximating to the fibulare.

While preparing the memoir above alluded to, Prof. Wyman kindly sent me some observations of his on the tarsus of the embryo Heron, which he generously allowed me to incorporate with my paper. Briefly, these consisted in his finding a long styleshaped bone, broadest at its distal extremity, lying in front, and at the distal end of the tibia, which he believed to represent the so-called ascending process of the astragalus, but which was shown to have an independent centre of ossification in the embryo, and to remain free from the other tarsal bones till the young had left the egg; when it appeared attached to the coëssified tibiale and fibulare, and presented the appearance not unlike that shown by Huxley in the young ostrich.

My interpretation at the time was that this new tarsal bone represented the intermedium, a tarsal bone which is clearly seen in the salamanders as ocöupying a position between the tibia and fibula, and indeed with half its length forced up, as it were, between these two bones.

I have previously shown that as the proximal series of tarsal bones became united, the fibula diminished in size proportionally with the rapid increase of the tibia, and became 
finally a splint bone, with its attenuated distal extremity far removed from the tarsus; the tibia on the contrary, enlarging, so that its distal extremity equalled in transverse diameter the two tarsal bones, which formed a cap on the end of the tibia, like an epiphysis, and finally became merged with it. The intermedium, while occupying its proper position between the tibiale and fibulare, and finally uniting with them, became apparently displaced, so to speak, by standing in front of the tibia.

This could be stated at the time with certainty: Namely, that the ascending process of the astragalus was an independent bone, which finally united with the proximal series of tarsal bones, and that a similar process in the young ehick and ostrich, as figured by Huxley, and a similar spur or process as seen in the astragalus of Laelaps and some other Dinosaurs, was to be looked upon as of the same nature.

To prove the correctness of this interpretation as to whether this bone was the intermedium, it was necessary to examine the early embryo, and to find, if possible, the bone occupying its true position in the tarsal series, and between the distal extremity of the tibia and fibula.

Believing that low aquatie birds would more readily yield these evidences, a visit was made to Grand Menan, at the mouth of the Bay of Fundy, and at that place were obtained the embryos of the razorbill auk, eider duck, sea pigeon, herring gull and petrel.

At Penikese Island in Buzzard's Bay, an opportunity was offered of examining the embryos of the tern. Through the courtesy of the Smithsonian Institution, I had the gratification of examining embryos of the southern black-backed gull, and the large penguin collected by Dr. Kidder at Kerguelen Island, during the U. S. Transit of Venus Expedition, and the results of these examinations were communicated verbally at the meetings of the American Association for the Advancement of Science in 1874 (9) and 1875 .

With the hope of making these observations more complete, their publication was withleld at the time. Finding the opportunity of studying other aquatic birds still uncertain, these results, slight though they may be, are given.

The accompanying plate presents in outline the tarsal joint of the following birds: The common Tern, Sterna hirundo; Petrel, Procellaria pelagica; Eider Duck, Somateria mollissima; Sea Pigeon, Uria grylle; Common Guillemot, Lomvia troile; Herring Gull, Larus argentatus; Razor bill Auk, Utamania torda; Southern black backed Gull, Larus dominicanus, and Great Auk, Aptenodytes Pennanti.

An additional figure is added of the right hand limb of the Sea-pigeon, as it shows the appearance of rudimentary nails on the second and third fingers.

In the figures of Sterna hirundo, figs.1-4), different stages of the tarsus are represented: Fig. 1 shows the intermedium distinctly wedged between the tibia and fibula, with its distal end in line with the distal margins of the tibiale and fibulare. The centrale is still small. In a later stage, as represented in figs. 2,3 , and $\bullet$, the tibia has widened considerably, though the tibiale and fibulare have not yet united. The intermedium now appears in front of the tibia, though still on a line with the tibiale. The separation of the distal end of the fibula and its tarsal bone has increased. The centrale las slightly increased in size. In fig. 2 , the tibiale and fibulare have coalesced. The 
intermedium has been crowded out and up, so that its distal end is on a line with the proximal margin of the tibiale and fibulare. The centrale has increased in size so that its transverse diameter is equal to that of the three metatarsals, to which it finally becomes attached at a later stage.

In the Petrel, Procellaria pelagica, fig. 5, a stage is represented, similar to that of the Tern, fig. 2. A new tarsal bone appears. (indicated on the plate with a question mark), corresponding to the rudimentary first toe. This bone was clearly defined in both legs. In appearance it looks like the proximal end of the first inetatarsal bone, with its corresponding tarsal. In only one other bird has a bone at all resembling this been seen, and that is shown in the figure of the Eider Duck (fig. 8, indicated by a query mark). In this case it appears like a second tarsale. In both cases this bone appears on the tibial side of the leg. It will be unsafe to hazard a conjecture as to what this bone represents, without further examination of other species.

In the Sea Pigeon, Uria grylle, the intermedium is a prominent, wedge-shaped bone, and quite separate from the other tarsal bones, though the embryo was far advanced. Its large size is interesting in connection with the fact that the fore limb shows conspicuons rudimentary nails on the second and third fingers. (See figs. 11, 12.)

In fig. 8, the tarsus and a portion of the other bones of the leg of the Eider Duck, Somateria mollissima, are represented. In this embryo the intermedium was clearly seen between the tibia and fibula, the tibiale and fibulare being widely separated.

In the Herring Gull, Larus argentatus, the intermedium is not large, the near tarsal bones are about uniting, yet the intermedium is still free, and somewhat removed from them.

In the Southern Black backed-Gull, Larus dominicanus, the intermedium is in nearly the same condition. In the Great Auk, Aptenodytes Pennanti, the appearance of the very short metatarsal bones, and the short square phalangeal bones, is extremely interesting. The embryo was far advanced, as indicated by the long and prominent clavs tipping the toes. Yet the bones composing the foot are very rudimentary.

The embryo of this species, and also that of the Southern Black-backed Gull, had been preserved in strong alcohol for several years, and the cartilaginous portion of the tarsus was so opaque that nothing definite could be made out in regard to the other tarsal bones. The intermedium, however, in both species, was very distinct.

From these observations it is seen that the intermedium is present in embryo birds as a distinct tarsal bone; that at first it is in line with the near tarsal series, that is to say with the tibiale and fibulare, and also between these two bones, and consequently between the distal extremities of the distal ends of the tibia and fibula. As the tibiale and fibulare coalesce, the intermedium is crowded outward and upward, the tibia widening at the same time to an extent equal to the transverse diameter of the near tarsal series; the intermedium occupies'a position in front of the tibia, and fills a groove which is seen on the anterior face of the tibia. It is seen, furthermore, that the intermedium is the last bone to unite with the coössified tibiale and fibulare.

The intermedium varies greatly in size in the embryos of different species. It will probably be found of more common accurrence among the lower birds. 
In young birds of certain species it is seen as an ascending spur occupying the fossa on the lower anterior face of the tibia. In mature birds, as far as I have discovered, it becomes absorbed.

The wide, oblique, tendon-like bridge, which spans the fossa in the heron and many other birds, has no relation with the intermedium.

In Laelaps and some other Dinosaurian Reptiles, this bone is seen as an ascending spur of the coössified tibiale and fibulare. In Ornithotarsus, as figured by Professor Cope, an appearance of the tarsus is represented, which is not unlike that shown in the early stages of the Tern. See plate, fig. 1 .

It is possible that the intermedium in Ornithotarsus was a separate bone, and that it has been lost in the fossil, as a distinct grove or fossa is seen on the lower anterior face of the tibia, while no corresponding spur is seen on the tibiale, a slight elevation only being discernible.

Professor Marsh (10), in a paper on the Limbs of Sauranodon, an animal related to Ichthyosaurus, has presented some novel views in regard-to the homologies of the intermedium.

huncl The limb is there figured with the femur of the usual character. Its distal face having, however, three articular surfaces, to which are applied three bones in the shape of irregular formed disks; these he interprets as tibia, intermedium and fibula.

He suggests that the intermedium belongs to the epipodial, or second series of bones represented by the radius and ulna, and tibia and fibula, and that in the process of differentiation the intermedium has been crowded down into the mesopodial or first series of tarsal bones.

My interpretation, based on the admirable figure he presented, would be that the bone which he indicates as the intermedium is really the fibula, and the bone which he represents as the fibula, is an outer tarsal bone, which, with its metatarsal and phalangeal bone in series becomes obliterated in time; that in the process of differentiation the intermedium is as likely to be partially compassed by the distal extremities of the tibia and fibula, as that a third bone of this segment had been crowded down into the tarsal series. However this may be, Professor Marsh has discovered a most interesting stage in this highly primitive condition of the bones as shown in Sauranodon.

In the following outlines, figures are presented of a portion of the leg of a salamander, a number of embryo birds, young birds, and Dinosaurian reptiles. These are given in series, so that a comparison may be made between the different stages of the intermedium in each of these forms. In the first series, figs. 1, 2, 3, 4, the intermedium is seen as a separate bone. In the second series the intermedium has united with the other tarsal bones and assumes the appearance which has been described as the ascending process of the astragalus. In the third series a similar condition is seen.

For explanation of lettering, see explanation of plate. 'The lettering being the same with the exception that $t f$ indicates the tibiale and fibulare connate. 
Adult Salamander and Embryo Birds.

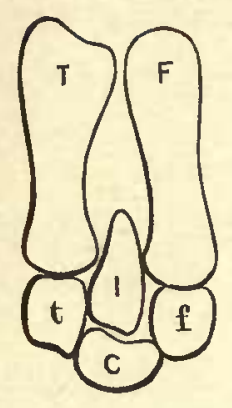

Fig. 1. Salamander.

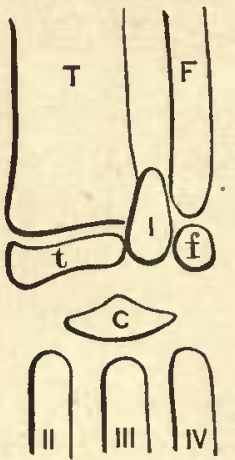

Fig. 2.
Tern.

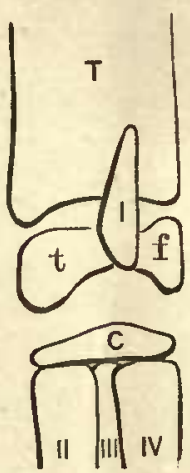

Fig. 3. Sea Pidgeon.

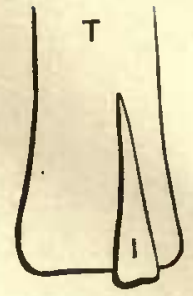

Fig. 4. Blue Heron.

Fig. 1. Fore leg of Salamandra maculosa, showing the intermedium, $i$, in its position between the distal ends of the tibia and fibula.

Fig. 2. Portion of leg of common Tern from an embryo, showing the appearance of the intermedium between the distal ends of the tibia and fibula.

Fig. 3. Portion of leg of the Sea Pigeon from an embryo with the intermedium in front of the tibia, from the widening of the tibia so as to compass in width the tarsal bones.

Fig. 4. Distal extremity of the tibia of the Blue Heron from an advanced embryo. In this figure only the intermedium is shown. Its distal end had not yet coössified with the other tarsal bones.

Young Birds.

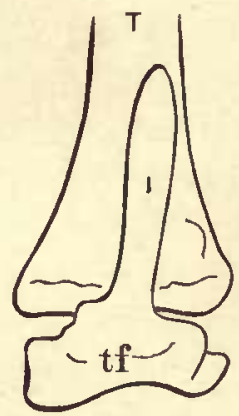

Fig. 5.

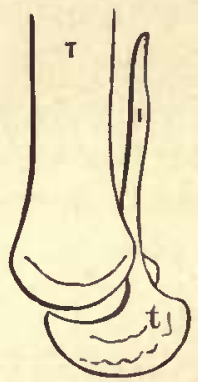

Fig. 6.

Young Ostrich.

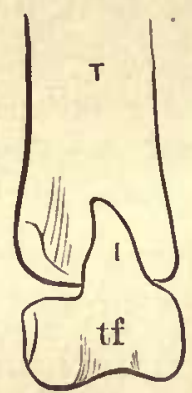

Fig. 7 .

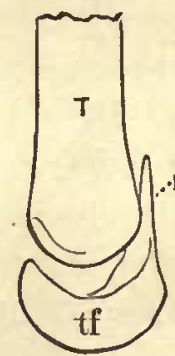

Fig. 8.

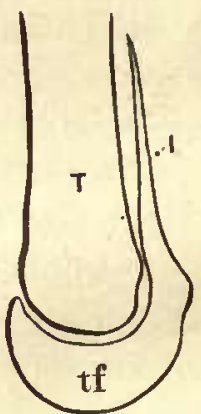

Fig. 9.

Young Blue Heron. Young Fowl.

Figs. 5 and 6 . Front and side views of the distal end of the tibia and tarsus of a young ostrich. From a figure of Professor Huxley's in Quarterly Journ. Geological Soc., above referred to. These figures show the tarsal bones including the.intermedium ankylosed together; the intermedium appearing as an ascending spur or process of the other tarsal bones.

Figs. 7 and 8. Front and side views of the distal end of tibia and tarsus of a young fowl, from Huxley's Anatomy of Vertebrated Animals, p. 253, fig. 88. The condition and general appearance are the same as in the figures of the young ostrich. 
Fig. 9. Side view of the distal end of tibia and tarsus of a young Blue Heron. The intermedium, as in the case of the young Ostrich and young fowl, has the appearance of an ascending spur from the other tarsal bones.

\section{Dinosaurian Reptines.}

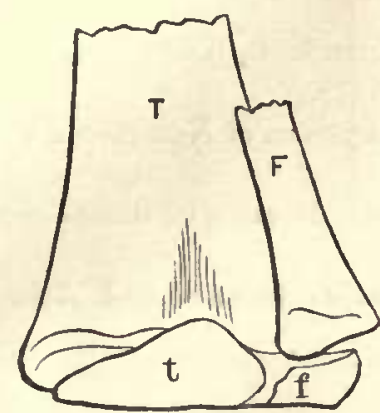

Fic. 10.

Ornitholarsus.

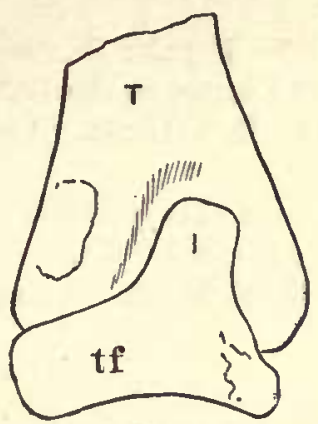

Fig. 11.

The "Honfleur Reptile."

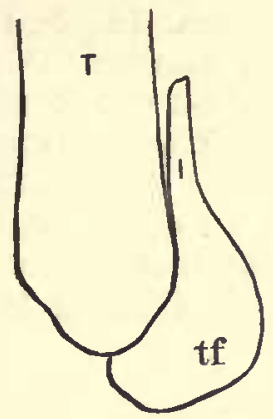

Fig. 12.

Laelaps.

Fig. 10. Distal extremities of the tibia and fibula of Ornithotarsus, after Cope's figure in Trans. Amer. Phil. Soc., Vol. xIv, fig. 35, page 122. The tibiale and fibulare are coössified. Whether the intermedium is represented by the enlargement of the tibiale in front, or was a separate bone which occupied the fossa on the anterior face of the tibia, is a matter of doubt. Ornithotarsus certainly presents a number of features that warrants its name.

Fig. 11. Distal end of tibia and tarsus of the "Honfleur Reptile," reduced from a figure in Cuvier's Ossemens Fossiles, described by Cuvier under the general head of Megalosaurus, without identification, afterwards named by Cope Laelaps gallicus. The intermedium is seen as a blunt portion ascending from the other tarsal bones.

Fig. 12. Distal end of tibia and tarsal bones of Laelaps; side view. Reduced from Cope's figure in 'Trans. Amer. Plil. Soc., Vol. xrv., plate 9. In this figure the intermedium is again seen as a long ascending spur in front of the tibia, but the coössified tibiale and fibulare occupy a far different position in relation to the distal articular face of the tibia from what is seen in birds.

\section{WORKS REFERRED TO.}

1. On the Anomalous Relations existing between the Tibia and Fibula in certain of the Dinosauria as illustrated by the genus Laelaps. Prof. Cope. Proc. Philad. Acad. of Sciences, Dec. 1866, p. 317.

2. An Account of the Extinct Reptiles which approach the Birds. Prof. Cope. Proc. of the Philad. Acad. of Sciences, Dec. 1867, p. 234.

3. Synopsis of the Extinct Batrachia, Reptilia and Ares of North America. Prof. Cope. Transactions of the American Philosophical Socicty, read Sept. 18, 1868, and April 2, 1869. 
4. On the Animals which are most Intermediate between Birds and Reptiles. Prof. Huxley. The Popular Science Review, No. xxzm, p. 237; being a Lecture delivered before the Royal Institution, Feb. 7. 1868.

5. Further Evidence of the Affinity between the Dinosaurian Reptiles and Birds. Prof. Muxley. Quart. Journ. Geological Soc. of London. Vol. xxvr. 1870.

6. Untersuchnngen zur vergleichenden Anatomie der Wirbeltheire. Erstes Heft; Carpus und Tarsus. Prof. Gegenbaur. Leipzig, 1864.

7. The Dinosauria. Prof. Seeley. The Popular Science Review, Jan. 1880, p. 44; being originally a Lecture delivered at the Scientific Club at Vienna, on the 19th of April, 1879.

8. On the Tarsus and Carpus of Birds. E. S. Morse. Annals of the Lyceum of Nat. Hist. N. Y., vol. 10 Art. vir. Read Jan. 29, 1872.

9. On the Ascending Process of the Astragalus in Birds. E. S. Morse. Meeting of the American Association for the Advancement of Science. Hartford, 1874.

10. On the Limbs of Sauranodon. Prof. Marsh. American Journal of Science and Arts, vol. XIX, Feb. 1880.

\section{EXPLANATION OF PLATE I.}

Fig. 1. Portion of left leg of embryo Tern.

Fig. 2. " " " " " " "

Fig. 3. " " " " " "

Fig. 4. " " " " " " " "

Fig. 5. Portion of right leg of embryo Petrel.

Fig. 6. " " left " " " Sea Pigeon.

Fig. 7. " " " " " " " $"$ "

Fig. 8. " " " " " " " " " "

Fig. 9. " " right " " " Southern black-back Gull.

Fig. 10. " " " " "

Fig. 11. " " right wing of embryo Sea Pigeon.

Fig. 12. " " " " " " " third finger more enlarged.

\section{EXPLANATION OF LETTERS.}

$F$, femur; $T$, tibia; $F$, fibula; $t$, tibiale; $f$, fibulare; $I$, intermedium; $c$, centrale ; ? tarsal bone of the second series? $U$, ulna; $R$, radius ; $u$, ulnare; $r$, radiale; 3,4 , third and fourth carpal bones ; I, II, III, IV, metacarpals. 


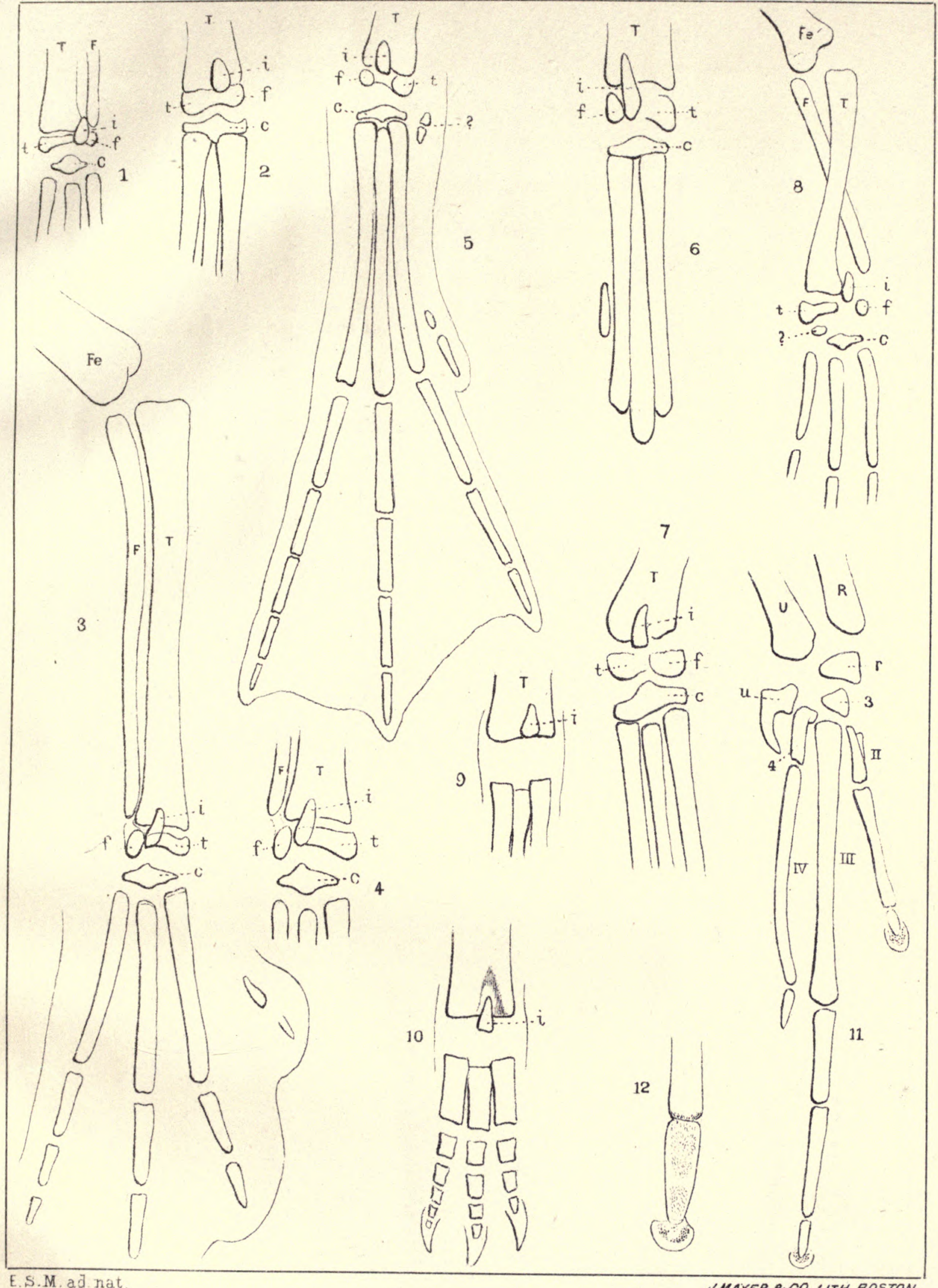

THE INTERMEDIUM IN BIRDS. 



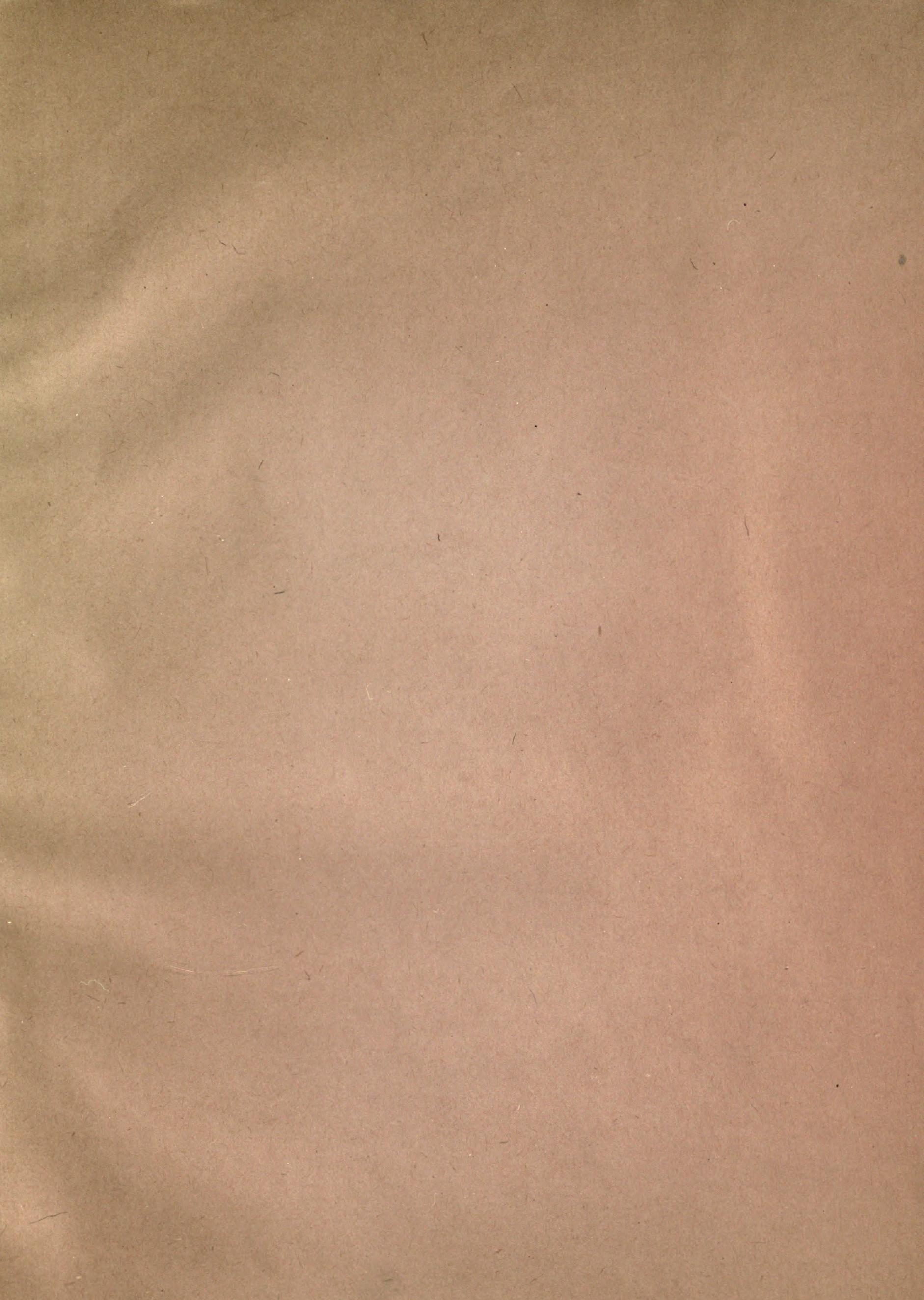





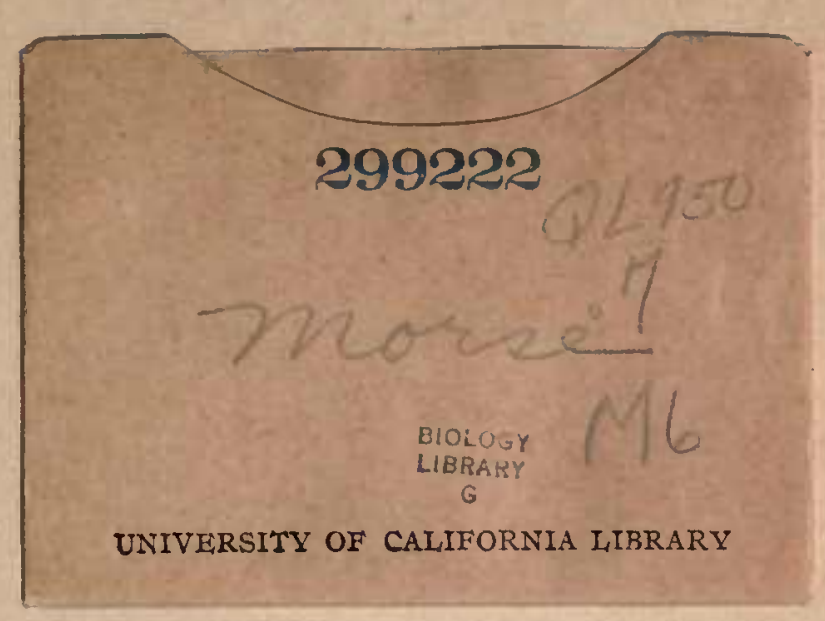


